gers lcave a point ${ }^{\prime} \mathrm{I} 2$ miles to the right of $\mathrm{S}$ and go to meet, somewhere between $S$ and $Z$, twenty-five passengers coming from a point io miles to the left of $Z$. How many miles from the right of $Z$ must they meet so that the one party spends just as much as the other party receives?

\title{
COOLING THROUGH A CHANGE OF STATE.
}

\author{
By C. K. Studley, \\ State Normal School, Chico, Cal.
}

This experiment is neither new nor original but follows the same lines as Exp. $2 \mathrm{r}$ in Millikan \& Gale's Lab. Course in Physics, but so far as I know the material used is new in this capacity, and is so simple and inexpensive that it ought to be of use to teachers of physics. The experiment referred to above calls for acetamide which is neither very cheap nor easy to obtain.

The apparatus necessary for this experiment is a thin walled test tube, a bunsen burner or alcohol lamp, a test tube holder, a thermometer and some sodium thiosulphate or ordinary hypo such as is used in fixing photos.

Fill the test tube nearly full of the crystals of hypo and carefully melt the crystals by holding over the gas jet or alcohol

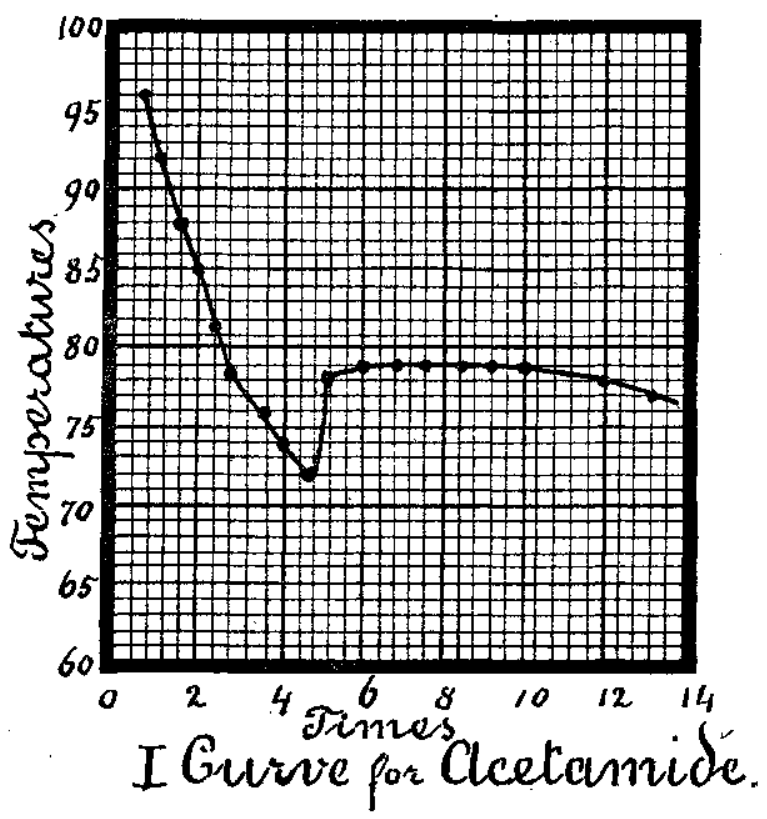


lamp. If they are heated carefully the temperature need never rise above $70^{\circ} \mathrm{C}$. or $75^{\circ} \mathrm{C}$. As soon as the crystals are all melted, insert the thermometer. Let it stand about half a minute and take the temperature. Take readings every minute, watching the liquid carefully. In an ordinary room it may be cooled to about $30^{\circ} \mathrm{C}$. or possibly a few degrees lower, but as soon as there ceases to be a marked change in the temperature drop in a fresh crysta! of hypo and note the results, at the same time continuing to take readings. The accompanying curve was

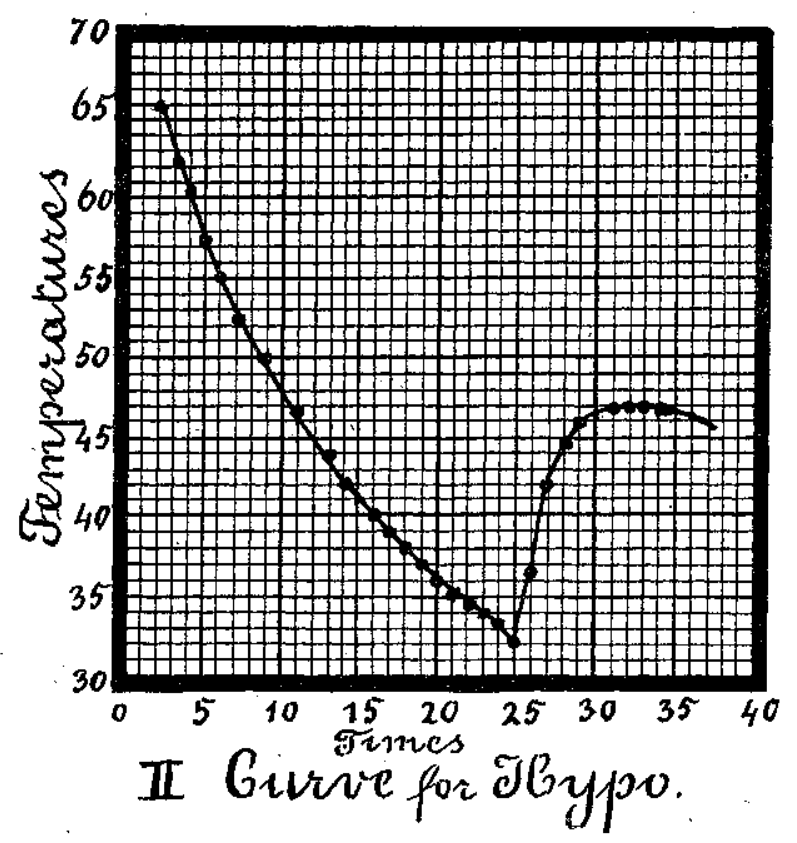

made in this way. Longer intervals, say two or even three minutes, could be taken if desired. For the sake of comparison I have reproduced the curve of cooling given for the acetamide in order that the advantages of the hypo may be readily seen.

If it is desirable to shorten the experiment, a relative curve may be made by putting the test tube into a dish of cold water as soon as the first reading is taken and taking readings every half minute. As soon as it is cooled to about $22^{\circ} \mathrm{C}$. or $23^{\circ} \mathrm{C}$. remove it from the water and drop in a crystal of hypo. This will show the heat of crystallization more strikingly than by the other methód and the time consumed by the entire experiment will be less than one fourth what it was in the other case. Below (Fig. 3) I give a curve obtained in this way. 
Comparing the two curves $I$ and 2 we will see that in the case of the acetamide as soon as crystallization begins the thermometer begins to rise and finally indicates a change of $7^{\circ} \mathrm{C}$... while in the case of the hypo there is a like rise of $15^{\circ} \mathrm{C}$. 'Take a glance at Curve 3 and it will be seen that there is a corre. sponding rise of $25^{\circ} \mathrm{C}$.

Hypo is not expensive and can be obtained with little difficulty so it seems that this alone ought to commend it to the teachers of physics.

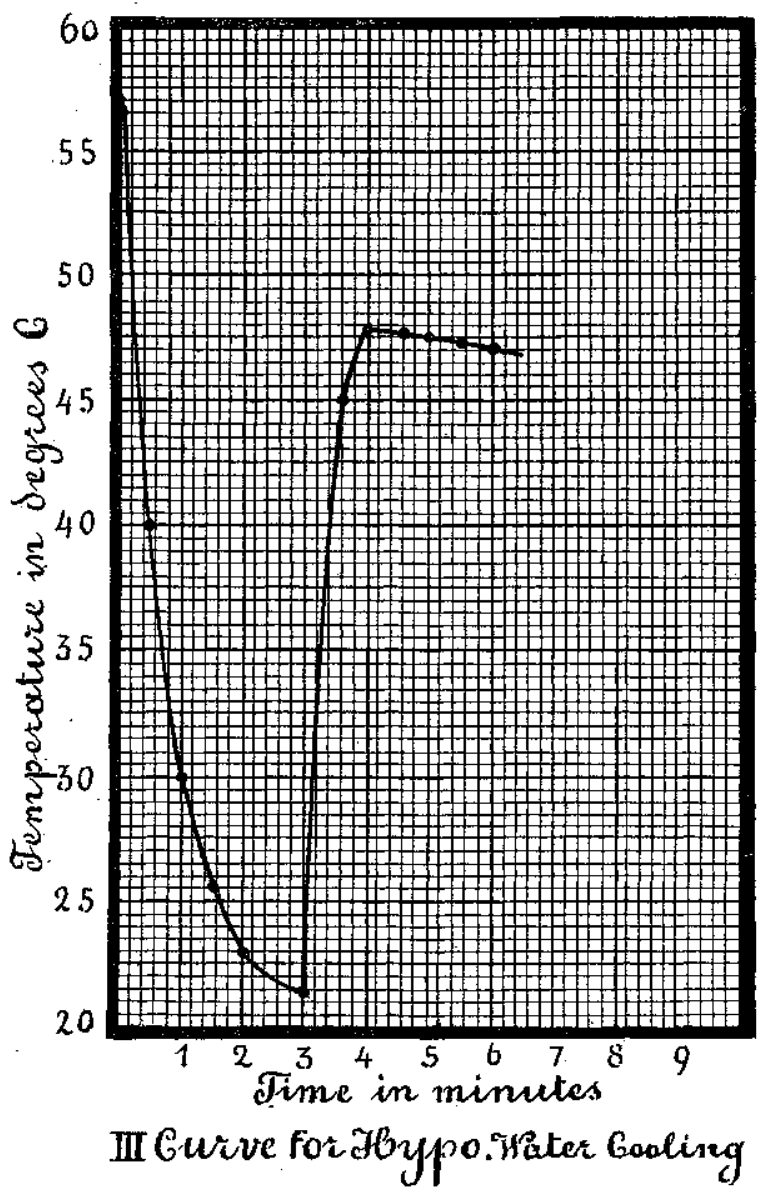

